$\S=-1$

\title{
Optimization on the Credit Risk of Companies in Malaysia With Data Envelopment Analysis Model
}

\author{
J. X. Agnes Lai ${ }^{1}$, W. H. Lam $^{1,2}$, W. S. Lam ${ }^{1,2 *}$ \\ ${ }^{I}$ Department of Physical and Mathematical Science, Faculty of Science, Universiti Tunku Abdul Rahman, Kampar Campus, 31900 Kam- \\ par, Perak, Malaysia \\ ${ }^{2}$ Centre for Mathematical Sciences, Centre for Business and Management, Universiti Tunku Abdul Rahman, Kampar Campus, 31900 \\ Kampar, Perak, Malaysia \\ *Corresponding authorE-mail: lamws@utar.edu.my
}

\begin{abstract}
Financial institutions provide financial services to their clients or retail customers where money is managed. Credit risk has been identified as one of the dominant risks that affect the performance of a company. A firm's efficiency with different credit risk management practices is still unknown. This research aims to evaluate the credit risk management and efficiency of the financial institutions that are publicly listed in Bursa Malaysia from year 2013-2016 with the Data Envelopment Analysis (DEA) model. Based on the financial ratios, the DEA model allows the relative efficiency of a set of companies to be assessed by solving a linear programming model. The results show that ALLIANZ, APEX, BURSA, ECM, LPI and TAKAFUL are efficient in terms of their credit risk management. This study identifies the efficient and inefficient financial companies in Malaysia.
\end{abstract}

Keywords: credit risk; data envelopment analysis; efficiency; linear programming model.

\section{Introduction}

It is well known that a bank serves as a financial intermediary, whereby it is a channel for the transaction to be done between two parties. For instance, payments made by one party will reach the bank before it is transferred to another party. Banks also act as a mediator by accepting deposits from public, as well as lending money to companies and individuals. Besides that, many other financial institutions are engaged with businesses that deal with various types of transactions such as investments and currencies exchange. Thus, the financial firms play a very crucial role in the financial system. A financially sound and well managed firm is of utmost importance for the continuous economic growth of a country.

Contribution of a financial firm towards the economic growth can be based on its performance efficiency, as it explains how the resources available can be efficiently used by a company in order to generate maximum outputs. Based on the Data Envelopment Analysis (DEA) model, the assessment of a firm's efficiency is achieved by comparing to a set of decision making units (DMUs) whereby the minimum possible inputs to produce a given set of outputs or the maximum possible outputs that can be generated from a set of inputs can be determined [1]. Since transactions can be performed anywhere and at anytime, risks that are often associated with financial transactions do exist anywhere and anytime.

Credit risk has a deleterious impact on a company during transactions. Credit risk is also known as default risk where it is the risk arises from borrowers and other counterparties who failed to make required payments on the promised date [2]. Credit risk is inevitable. The importance of having a proper credit risk management system is vital as failure to effectively manage credit risk might cause a firm to be insolvent. Ultimately, it will result in firm fail- ures. If credit risk management is not emphasized in a company and the credit scores of its clients are not properly evaluated, granting loans to those with poor credit rating will increase the probability of default. Relevant studies have been done by past researchers to compare and evaluate a firm's efficiency adjusted for credit risk. That being said, the awareness of credit risk management is on the rise.

Several analytical techniques have been proposed in addressing the issue of credit risk evaluation. Apart from that, the DEA model has been recognized as a useful tool to obtain the efficiency measures of firms. It has been applied in areas such as banking industry [3, 4], manufacturing industry [5-7], healthcare industry [8], as well as the chemical sector [9]. Nevertheless, no comprehensive study is found on the assessment of credit risk-adjusted efficiency of the financial firms in Malaysia. Therefore, the DEA model is proposed in this study to evaluate the relative efficiency of the financial institutions with respect to credit risk. The evaluation of efficiency scores associated with credit risk by employing the DEA model was first introduced by [10]. Since then, a number of studies attempted to obtain the credit risk-adjusted efficiency by utilizing the DEA model. DEA model is shown to be applicable for the prediction of company failures.

DEA method was first developed by [11]. It is a nonparametric approach in which it requires no assignment of weights to the inputs and outputs, measuring productive efficiency through the application of linear programming. The relative efficiency of a DMU is measured based on the ratio of sum weighted outputs to the sum weighted inputs [12]. Upon obtaining the efficiency scores, DEA model helps the decision maker to categorise the DMUs into two groups, the efficient and inefficient group. The results obtained from the analysis are measured in terms of efficiency and it varies between 0 and 1 . The efficiency scores can be converted into percentage, where it ranges from $0 \%$ to $100 \%$. A 
unit is considered as efficient or so called a "best practice" unit if it attains a score of 1 or $100 \%$. An efficient unit lies at the efficiency frontier, where the resources of a unit are used efficiently to generate the maximum possible outputs or the use of inputs can be minimized from a given set of outputs. On the contrary, a unit that scores less than 1 is considered as relatively inefficient. Therefore, this study aims to assess and compare the credit risk management and relative efficiency of the financial institutions in Malaysia with DEA model.

The paper will be structured as follows. It begins with an introduction to credit risk and the DEA model. In Section 2, it is the methodology of the study. Further in Section 3, the results will be displayed and there will be a discussion based on the overall results obtained. The last section draws a conclusion for the study and summarizes the main topics covered in this paper.

\section{Methodology}

\subsection{Data}

The data of this study consists of the listed companies in the financial sector of Bursa Malaysia [13]. The data is obtained from the financial statements of these firms in year 2013-2016. In this study, the inputs are debt to assets ratio, current liabilities ratio, and debt to equity ratio. As for the outputs, the financial ratios are return on equity (ROE), return on assets (ROA), and current ratio. Based on the literature search, these are the important indicators that measure the financial performance of firms [4, 5, 14].

Debt to assets ratio measures how leveraged a firm is and it is defined as a proportion of total debt to total assets [15]. In order to quantify the stability of a capital structure, current liabilities ratio is used. Current liabilities ratio indicates the ratio of current liabilities to owners' equity [4]. In addition to that, debt to equity ratio measures the proportion of shareholders' equity and debt that are used to finance a firm's assets. Hence, a higher debt to equity ratio implies that a company relies on a significant amount of debt to fund its assets. ROE is a financial ratio that measures the profit earned from every unit of the owner's equity [16]. The higher the ROE, the more efficient the firm is at utilizing the money invested by the shareholders [17]. ROA indicates the profit generated from the money spent on the company assets [18]. Current ratio on the other hand, measures the firm's ability to meet its short-term obligations with its current assets [19]. The greater the current ratio is, the better the liquidity of the firm is $[5,13]$. A firm with good liquidity tends to be able to fulfil its contractual obligations.

\subsection{Data Envelopment Analysis (DEA)}

The DEA model is widely applied in various fields for the assessment of performance efficiency. DEA is a linear programming model that allows multiple inputs and outputs, whereby the relationship between them can be best estimated. It assists researchers to categorise the DMUs into two distinct groups, the efficient and the inefficient group. There are two main models under the DEA, namely CCR model and BCC model. The CCR model was further improved and extended to BCC model [20]. BCC is a model that identifies whether the unit is operating under constant, increasing or decreasing return to scale. The formulation of BCC model is shown as follows.

Maximize $h_{k}=\frac{\sum_{r=1}^{s} t_{r} y_{r k}+\alpha}{\sum_{i=1}^{m} w_{i} x_{i j}}$

Subject to

$$
\begin{aligned}
& \frac{\sum_{r=1}^{s} t_{r} y_{r j}+\alpha}{\sum_{i=1}^{m} w_{i} x_{i j}} \leq 1, j=1,2,3, \ldots, n \\
& t_{r} \geq \varepsilon, r=1,2,3, \ldots, s \\
& w_{i} \geq \varepsilon, i=1,2,3, \ldots, m
\end{aligned}
$$

where $h_{k}$ is the relative efficiency of $\mathrm{DMU}_{\mathrm{k}}, S$ is the number of outputs, $t_{r}$ is the weights to be determined for output $r, y_{r j}$ is the observed magnitude of r-type output for entity $j, m$ is the number of inputs, $w_{i}$ is the weights to be determined for input $i$, $x_{i j}$ is the observed magnitude of i-type input for entity $j, \mathrm{n}$ is the number of DMUs, $\varepsilon$ is the positive value and $\alpha$ is the free variable.

In (1) is an objective function which maximizes the efficiencies of the DMUs. In (2) restricts the efficiency of each measured unit, ensuring the efficiency to range between 0 to $1 . t_{r}$ and $w_{i}$ are the weights that measure the importance of each output and input respectively in maximizing the efficiency of the DMUs. The model above is a nonlinear model and it can be reduced to its linear form.

Maximize $h_{k}=\sum_{r=1}^{s} t_{r} y_{r k}+\alpha$

Subject to

$\sum_{i=1}^{m} w_{i} x_{i j}-\sum_{r=1}^{s} t_{r} y_{r j}-\alpha \geq 0, j=1,2,3, \ldots, n$

$\sum_{r=1}^{m} w_{i} x_{i k}=1$

$t_{r} \geq \varepsilon, r=1,2,3, \ldots, s$

$w_{i} \geq \varepsilon, i=1,2,3, \ldots, m$

In this study, LINGO software is used to solve the DEA model. LINGO is an optimization software for solving linear programming model, non-linear programming model, goal programming model and integer programming model.

\section{Results and Discussion}

The results of the performance efficiency and the ranking of the financial companies are presented in Table 1 and Fig. 1 respectively.

Table 1: Ranking of the Financial Companies

\begin{tabular}{|c|c|c|}
\hline DMU & Efficiency $(\%)$ & Rank \\
\hline ABMB & 29.35 & 13 \\
\hline AEONCR & 72.24 & 3 \\
\hline AFFIN & 28.51 & 15 \\
\hline ALLIANZ & 100.00 & 1 \\
\hline AMBANK & 29.12 & 14 \\
\hline
\end{tabular}




\begin{tabular}{|c|c|c|}
\hline APEX & 100.00 & 1 \\
\hline BIMB & 40.88 & 7 \\
\hline BURSA & 100.00 & 1 \\
\hline CIMB & 20.49 & 20 \\
\hline ECM & 100.00 & 1 \\
\hline ELKDESA & 82.66 & 2 \\
\hline HLBANK & 29.74 & 12 \\
\hline HLCAP & 38.18 & 9 \\
\hline HLFG & 29.75 & 11 \\
\hline INSAS & 59.32 & 5 \\
\hline JOHAN & 1.66 & 26 \\
\hline KENANGA & 4.96 & 25 \\
\hline LPI & 100.00 & 1 \\
\hline MAA & 55.90 & 6 \\
\hline MANULFE & 14.12 & 24 \\
\hline MAYBANK & 27.78 & 17 \\
\hline MBSB & 27.38 & 18 \\
\hline MNRB & 23.66 & 19 \\
\hline MPHBCAP & 34.30 & 10 \\
\hline $\mathrm{P} \& \mathrm{O}$ & 28.44 & 16 \\
\hline PBBANK & 39.88 & 8 \\
\hline RCECAP & 15.07 & 23 \\
\hline RHBBANK & 19.98 & 22 \\
\hline TA & 20.10 & 21 \\
\hline TAKAFUL & 100.00 & 1 \\
\hline TUNEPRO & 60.73 & 4 \\
\hline
\end{tabular}

MPHBCAP, P\&O, PBBANK, RCECAP, RHBBANK, TA and TUNEPRO are found to be inefficient with respect to their credit risk management. As shown in Table 1 and Fig. 1, the efficiency scores obtained by these companies are lower than $100.00 \%$. ELKDESA is ranked second among 31 of the public listed companies as it achieved an efficiency score of $82.66 \%$. TUNEPRO is ranked after ELKDESA where it obtained the third ranking in this study as it scored $72.24 \%$ efficiency. It is worth noting that KENANGA and JOHAN performed poorly in terms of credit riskadjusted efficiency as their efficiency scores are $4.96 \%$ and $1.66 \%$ respectively. Both of these companies obtained a relatively low efficiency as both of their efficiency scores are below $10.00 \%$.

In summary, ALLIANZ, APEX, BURSA, ECM, LPI and TAKAFUL are the six financial companies in Malaysia that are found to be operating efficiently in terms of their credit risk management. Therefore, other inefficient financial companies can review their credit risk practices by taking the efficient companies as a benchmark in order to improve their efficiency.

\section{Conclusion}

DEA evaluates the relative efficiency of the companies by solving a linear programming model. This study aims to assess and evaluate the credit risk management and efficiency of the financial institutions in Malaysia with the DEA model. The efficient and inefficient financial companies in Malaysia are identified in this study. Being efficient implies that these companies have optimal control over their outputs in order to generate maximum outputs. In addition, the efficient firms will serve as a benchmark for the inefficient firms so that further improvement can be made in order to achieve optimal efficiency

\section{Acknowledgement}

This study is supported by Universiti Tunku Abdul Rahman.

\section{References}

[1] Ferus A. The DEA method in managing the credit risk of companies. Ekonomika, 2008, 84: 109-118

[2] Keramati M A, Shaeri M. Assessment of credit risk management and managerial efficiency of banks using Data Envelopment Analysis (DEA) network. Biological Forum - An International Journal, 2014, 6(2): 320-328

[3] Chiu Y-H, Ma C-M, Sun M-Y. Efficiency and credit rating in Taiwan banking: Data Envelopment Analysis estimation. Applied Economics, 2010, 42(20): 2587-2600

[4] Lu S-L, Lee K-J, Zou M-L. How to gauge credit risk: An investigation based on Data Envelopment Analysis and the Markov Chain model. Applied Financial Economics, 2012, 22(11): 887-897

[5] Min J H, Lee Y C. A practical approach to credit scoring. Expert Systems with Applications, 2008, 35(4): 1762-1770

[6] Lam W H, Lam W S, Liew K F. Improvement on the efficiency of technology companies in Malaysia with Data Envelopment Analysis model. Lecture Notes in Computer Science, 2017, 10645: 19-30

[7] Lam W S, Liew K F, Lam W H. An optimal control on the efficiency of technology companies in Malaysia with Data Envelopment Analysis model. Journal of Telecommunication, Electronic and Computer Engineering, 2018, 10(1): 107-111

Based on Table 1 and Fig. 1, six out of 31 of the public listed financial companies evaluated are found to be efficient as they have attained an efficiency score of $100.00 \%$. The financial analysis is conducted with the BCC model. The six efficient firms are ALLIANZ, APEX, BURSA, ECM, LPI and TAKAFUL. Obtaining an efficiency score of $100 \%$ indicates that these companies are able to manage their exposure to credit risk efficiently. In essence, the inputs or resources of the companies are used optimally in order to generate maximum outputs or outcomes. Hence, the six efficient companies are ranked first in Table 1.

On the contrary, ABMB, AEONCR, AFFIN, AMBANK, BIMB, CIMB, ELKDESA, HLBANK, HLCAP, HLFG, INSAS, JOHAN, KENANGA, MAA, MANULFE, MAYBANK, MBSB, MNRB,

[8] Lam W S, Liew K F, Lam W H. An empirical comparison on the efficiency of healthcare companies in Malaysia with Data Envelopment Analysis model. International Journal of Service Science, Management and Engineering, 2017, 4(1): 1-5

[9] Tsolas I E. Firm credit risk evaluation: A series two-stage DEA modeling framework. Annals of Operations Research, 2015, 233(1): 483-500

[10] Troutt M D, Rai A, Zhang, A. The potential use of DEA for credit applicant acceptance systems. Computers and Operations Research, 1996, 23(4): 405-408

[11] Charnes A, Cooper W W, Rhodes E. Measuring the efficiency of decision making units. European Journal of Operational Research, 1978, 2(6): 429-444 
[12] Hadad Y, Friedman L, Sinuany-Stern Z, Ben-Yair A. Ranking method based on the difference between weighted output and input. Computer Modelling and New Technologies, 2008, 12(3): 55-65

[13] Bursa Malaysia, Company Announcements | Bursa Malaysia Market. http://www.bursamalaysia.com/market/listedcompanies/company-announcements/\#/?category=all.

[14] Li H, Pang S. The study of credit risk evaluation based on DEA method. Proceedings of the International Conference on Computational Intelligence and Security, 2010, pp. 81-85

[15] Moyer R C, McGuigan J R, Rao R P. Contemporary financial management. Cengage Learning, 2018.

[16] Ledgerwood J. Microfinance handbook: An institutional and financial perspective. The World Bank, 1999.

[17] Loughran M. Intermediate accounting for dummies. John Wiley and Sons, 2011.

[18] Bucci R V. Medicine and business: A practitioner's guide. Springer, 2014.

[19] Colombo E, Stanca L. Financial market imperfections and corporate decisions: Lessons from the transition process in Hungary. Physica-Verlag Heidelberg, 2006.

[20] Banker RD, Charnes A, Cooper WW. Some models for estimating technical and scale inefficiencies in data envelopment analysis. Management Science, 1984, 30(9): 1078-1092. 